\title{
Molecular Docking Studies of Shc1 Protein: A Drug Target to Treat Obesity
}

\author{
Shobha Shouche ${ }^{1}$, Sachin Rahangdale ${ }^{1 *}$, Ravikant Yadav ${ }^{1}$, Harshad Sharma ${ }^{2}$ \\ ${ }^{I}$ govt. Madhav science college, ujjain, madhya pradesh, india \\ ${ }^{2}$ school of studies microbiology department vikram university ujjain, madhya pradesh, india
}

\begin{abstract}
Scientists recently identified the important role of SHC1 gene expression in causing obesity. SHC1 protein has been found to be highly active in fatty tissues. It could help to develop medicines to treat obesity and related diseases such as heart disease, diabetes, cancer etc. In this present work, based on protein-ligand interaction studies, we proposed interacting domain for SHC1 (PDBID: 1N3H) and further the interacting domain was chosen to screen with a set of natural compounds. At last the potent lead molecules with good docking score were screened for their ADMET properties. The best inhibitor has been reported here.

Key words: Inhibitor, Ligand, Docking, Interaction, Screen
\end{abstract}

\section{Introduction}

Obesity is a complex disorder involving an excessive amount of body fat. Obesity isn't just a cosmetic concern. It increases your risk of diseases and health problems such as heart disease, diabetes and high blood pressure. In the present scenario, childhood obesity is a major public health problem. Globally, in 2010 there were 42 million children were estimated to be overweight below the age of 5, and 35 million of them are from urban areas of developing countries [11]. In India, nearly 15 to $20 \%$ of children are overweight. Many studies have shown that the prevalence of overweight among adolescents varies between $10 \%$ and $30 \%$ in India [12][13].

Obesity treatments may include changes in lifestyle, exercise, dieting and weight loss medicines or bariatricsurgery. The surgeryis reserved for people with severe obesity who has not responded to other weight loss therapy [14].

Some weight loss drugs are associated with dangerous heart and lung side effects. Many of the weight loss drugs known as sympathomimetic amines can stimulate the heart and lead to high blood pressure and tachycardia (fast heart beat). These drugs may be associated with constipation, dry mouth, restlessness, withdrawal effects, or insomnia (difficulty falling asleep) [6].

In this present work, based on protein-ligand interaction studies [9], we proposed interacting domain for SHC1 (PDBID: 1N3H) and further the interacting domain was chosen to screen with a set of natural compounds. At last the potent lead molecules with good docking score were screened for their ADMET properties.

\section{Natural Ligands Collections}

\section{Material And Methodology}

All natural ligands were collected from supernatural V II database [1]. These ligands were of natural origin. These targets were selected from the pathway diabetes mellitus type-2.

\section{Target Protein Preparations}

Target protein with PDBID: 1N3H was downloaded from PDB [2]. This protein was checked and fixed for any missing residues, loops, bond length in "macromolecule" module of SPDBV [v4.1.0][8]. Then this structure was optimized and minimized.In the crystal structure of SHC-transforming protein -1 PTB domain of chain A was taken as active site was chosen for grid generation as there was already a crystal inhibitor. Grid was made using "define site" module of MVD.

\section{Ligandselection}

All the collected ligands from supernatural V II database were checked on the basis of Lipinski's rule. This rule is helpful to identify the molecules. Whether it can be used as a drug like or not. It means that it can predict the success probability rate of a molecule.

The molecules should have the following properties according to rules.

MW --------0 to 500
Xlogp------0 to 5
HBD-------0 to 5


HBA -0 to 10

On the basis of above parameter we have selected 4 ligands for this study and found perfect for Potent and ADMET study.

\title{
Docking Studies And Interaction Studies
}

A molecular docking study was done with naturalligands and protein from Genetic optimization for ligand docking Molegro Virtual Docker (MVD 4.0.2)[7]. We find interactions from MVD in terms of good scoring function and search space. We find active sites from MVD and cross checked with Active site prediction [5]

\begin{abstract}
ADME Analysis And Best Ligand Proposal
ADMET stands for Absorption, Distribution, Metabolism, Excretion and Toxicity. If a ligand follows ADMET properties then its likeness to become a drug molecule increases. Pharmacokinetics and Pharmacodynamic come under ADMET studies. We have used OSIRIS PROPERTY EXPLORER [3] to check whether they are obeying all the ADMET properties or not.

On the basis of non-bonded and bonded interactions, ADMET properties and scoring functions, we can propose these ligands as apotent inhibitors of SHC-transforming protein -1(PTB domain). OSIRIS PROPERTY EXPLORER [3] was used to know the mutagenicity, carcinogenicity, reproductively and toxicity. Red color indicates its unfavorability to consume as a drug while green color indicates its favorability to consume as druglike.
\end{abstract}

\section{Result And Discussion}

Total 80 natural ligands were collected which act as potent natural drugs for the following targets in diabetes mellitus type 2 .

SN00000362, SN00001731, SN00001876, SN00002040, SN00002047,SN00000245, SN00002211, SN00002222, SN00002257, SN00002387, SN00002543, SN00003330, SN00005643, SN00005648, SN00005681, SN00006216, SN00006577, SN00008119, SN00011332, SN00011568, SN00014213, SN00017871, SN00017872, SN00017873, SN00017874, SN00021320, SN00024335, SN00024491, SN00027401，SN00029289, SN00030295, SN00030296, SN00032737， SN00032738, SN00032739, SN00032740, SN00035548, SN00037188, SN00037189, SN00037510, SN00037511, SN00037512, SN00037513, SN00038410, SN00038512, SN00038784, SN00038948, SN00039296, SN00039297, SN00041720, SN00041721, SN00048679, SN00048687, SN00048690, SN00048700, SN00050524, SN00050528, SN00050529, SN00050552,SN00051430, SN00051747, SN00064236, SN00064237, SN00064343, SN00064344, SN00064345, SN00064435, SN00064441，SN00064442, SN00064551, SN00067564, SN00078039, SN00078040, SN00089453, SN00121987, SN00126359, SN00127648, SN00127649, SN00001023, SN00000558

SHC-transforming protein -1 was downloaded from PDB with ID 1N3H and find the key active site residues from MVD and cross checked with active site prediction. (Volume of cavity $=640.99$ ).

To propose ligands to inhibit SHC-transforming protein -1, we have selected 4 ligands compound, which follow the lipinski's rule of five.

The proposed best 4 ligands are given in Table 1 .

Table 1: Best 4 compounds as inhibitor to SHC-transforming protein -1

\begin{tabular}{|l|l|}
\hline Compound ID & Compound name \\
\hline SN00000245 & Resveratrol \\
\hline SN00000362 & 6-hydroxy-2-(3-methoxyphenyl)chromen-4-one \\
\hline SN00001023 & cis-dihydroquercetin \\
\hline SN00000558 & 2-(3,4-dimethoxyphenyl)benzo[h]chromen-4-one \\
\hline
\end{tabular}

Note: Highlighted compound is most important ligands following ADME properties and good scoring function. 
Table 2: proposed ligands structure

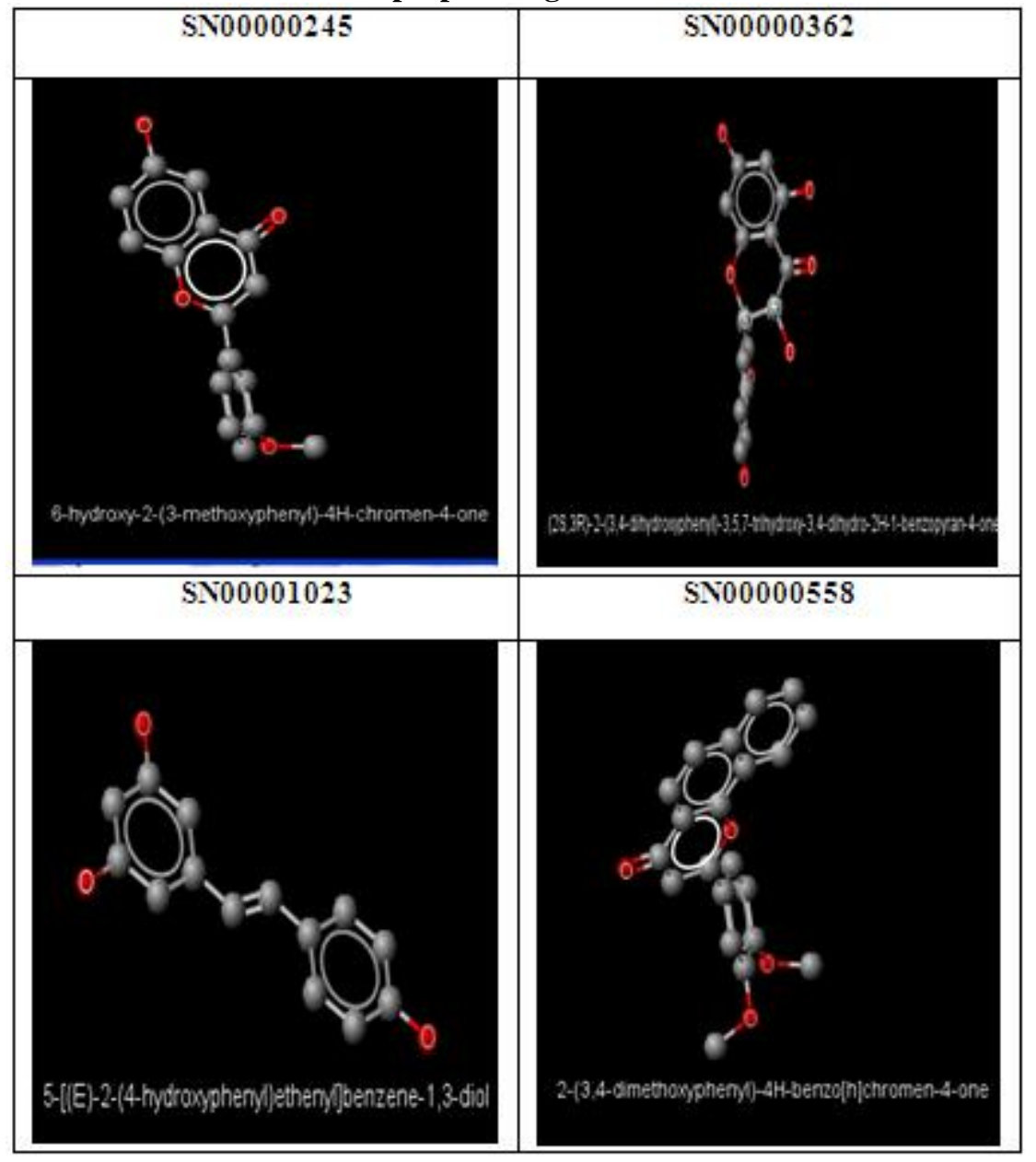

Table3: Basic descriptors for ligands is shown in Table 3

\begin{tabular}{|c|c|c|}
\hline Ligand & Descriptors & \\
\hline \multirow[t]{15}{*}{ SN00000245 } & Name & resveratrol \\
\hline & Molecular weight & 228.079 \\
\hline & Formula & $\mathrm{C}_{14} \mathrm{H}_{12} \mathrm{O}_{3}$ \\
\hline & desolv polar & $\begin{array}{ll}-8.46 \\
\end{array}$ \\
\hline & desolv apolar & 0.79 \\
\hline & H-bond donors & $\begin{array}{ll}3 \\
\end{array}$ \\
\hline & $\mathrm{H}$-bond acceptors & 0 \\
\hline & TPSA & 61 \\
\hline & Charge & $\begin{array}{ll}0 \\
\end{array}$ \\
\hline & NRB & 2 \\
\hline & $\log$ & 2.9738 \\
\hline & Ring count & 2 \\
\hline & Atom count & 29 \\
\hline & Bond count & 18 \\
\hline & SMILES & $\mathrm{c} 1 \mathrm{cc}(\mathrm{ccc} 1 / \mathrm{C}=\mathrm{C} / \mathrm{c} 1 \mathrm{cc}(\mathrm{cc}(\mathrm{c} 1) \mathrm{O}) \mathrm{O}) \mathrm{O}$ \\
\hline \multirow[t]{15}{*}{ SN00000362 } & Name & 6-hydroxy-2-(3-methoxyphenyl)chromen-4-one \\
\hline & Molecular weight & 268.074 \\
\hline & Formula & $\mathrm{C}_{16} \mathrm{H}_{12} \mathrm{O}_{4}$ \\
\hline & desolv polar & -11.73 \\
\hline & desolv apolar & 4.73 \\
\hline & H-bond donors & 1 \\
\hline & H-bond acceptors & 1 \\
\hline & TPSA & 60 \\
\hline & Charge & 0 \\
\hline & NRE & 2 \\
\hline & $\log p$ & 3.1742 \\
\hline & Ring count & 3 \\
\hline & Atom count & 32 \\
\hline & Bond count & 22 \\
\hline & SMILES & $\operatorname{coc} 1 \operatorname{cccc}(c 1) \operatorname{coc} 1 \mathrm{cc}(=0) \mathrm{c} 2 \mathrm{cc}(\mathrm{ccc} 201) \mathrm{O}$ \\
\hline
\end{tabular}


Molecular Docking Studies of Shc1 Protein: A Drug Target to Treat Obesity

\begin{tabular}{|c|c|c|}
\hline \multirow[t]{15}{*}{ SN00001023 } & Name & cis-dihydroquercetin \\
\hline & Molecular weight & 304.058 \\
\hline & Formula & $\mathrm{C}_{15} \mathrm{H}_{12} \mathrm{O}_{7}$ \\
\hline & desolv polar & -13.46 \\
\hline & desolv apolar & -4.11 \\
\hline & $\mathrm{H}$-bond donors & 5 \\
\hline & $\mathrm{H}$-bond acceptors & 2 \\
\hline & TPSA & 127 \\
\hline & Charge & 0 \\
\hline & NRB & 1 \\
\hline & $\log p$ & 1.1863 \\
\hline & Ring count & 3 \\
\hline & Atom count & 34 \\
\hline & Bond count & 24 \\
\hline & SMILES & $c 1 c c(c(c c 1[c @ H] 1[\mathrm{C} @ H](C(=0) c 2 c(c c(c c 201) 0) 0) 0) d$ \\
\hline \multirow[t]{15}{*}{ SN00000558 } & Name & 2-(3,4-dimethoxyphenyl)benzo[h]chromen-4-one \\
\hline & Molecular weight & 332.105 \\
\hline & Formula & $\mathrm{C}_{21} \mathrm{H}_{16} \mathrm{O}_{4}$ \\
\hline & desolv polar & -12.99 \\
\hline & desolv apolar & 2.6 \\
\hline & $\mathrm{H}$-bond donors & 0 \\
\hline & $\mathrm{H}$-bond acceptors & 1 \\
\hline & TPSA & 49 \\
\hline & Charge & 0 \\
\hline & NRB & 3 \\
\hline & $\log p$ & 4.6304 \\
\hline & Ring count & 4 \\
\hline & Atom count & 41 \\
\hline & Bond count & 28 \\
\hline & SMILES & $\operatorname{coc} 1 \operatorname{ccc}(\operatorname{cc} 10 \operatorname{coc} 1 \operatorname{cc}(=0) \operatorname{coc} 3 \operatorname{ccccc} 3 \mathrm{c} 201$ \\
\hline
\end{tabular}

After ligands validation we performed Molecular docking studies of SHC-transforming protein -1with these proposed four ligands. Molecular Docking Score are given in Table 4.

Table 4: Molecular docking Results

\begin{tabular}{|l|l|l|l|}
\hline Ligand & H-bond & Moldock score (Energy) & RMSD \\
\hline SN00000245 & 6 & -84.86 & 0.0088 \\
\hline SN00000362 & 3 & -99.05 & 0.33 \\
\hline SN00001023 & 6 & -100.38 & 0.02 \\
\hline SN00000558 & 3 & -76.13 & 0.008 \\
\hline
\end{tabular}

The table 5 is shows the favorable interactions between ligand-protein. The following diagram labels are used in Molegro Virtual Docker (MVD 4.0.2). These Diagrams show Hydrogen bond interaction, hydrophobic interaction and Electrostatic interaction of 4 best ligands with target proteins.

Table 5: Electrostatic, Hydrophobic and $H$ bond interaction of 4 best ligands with target proteins.

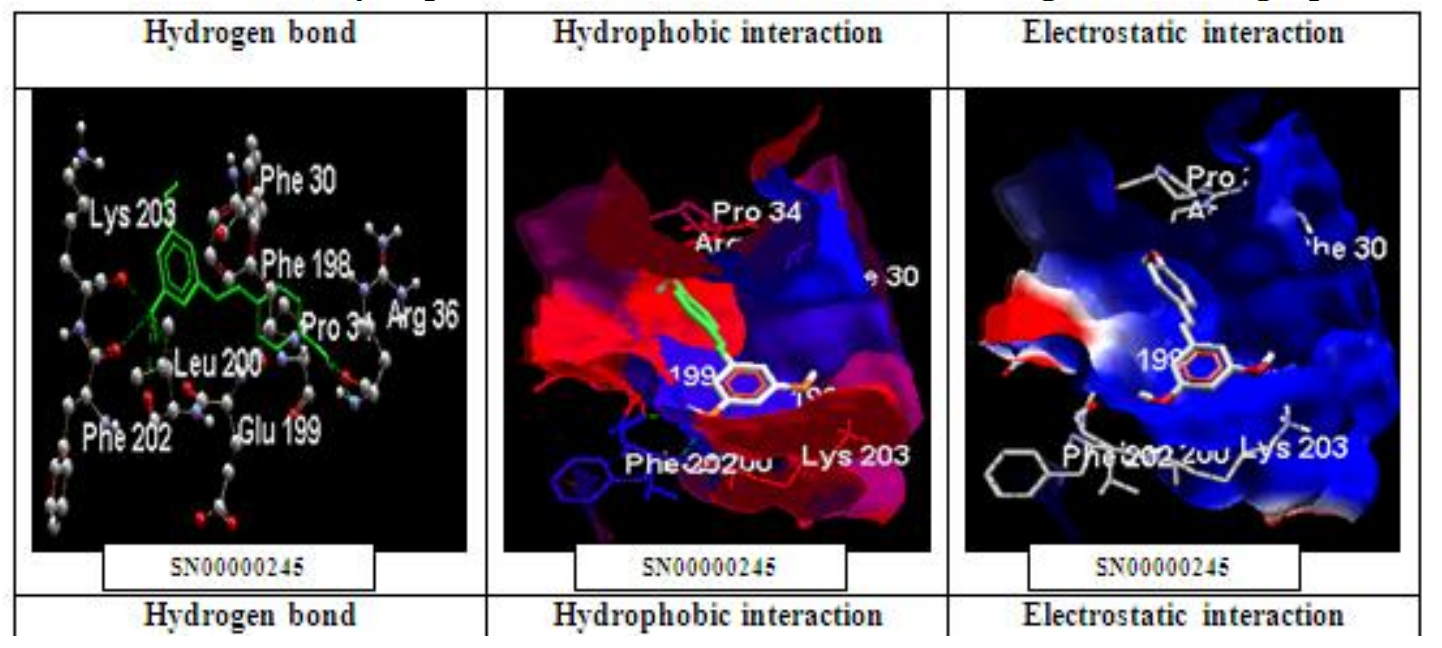



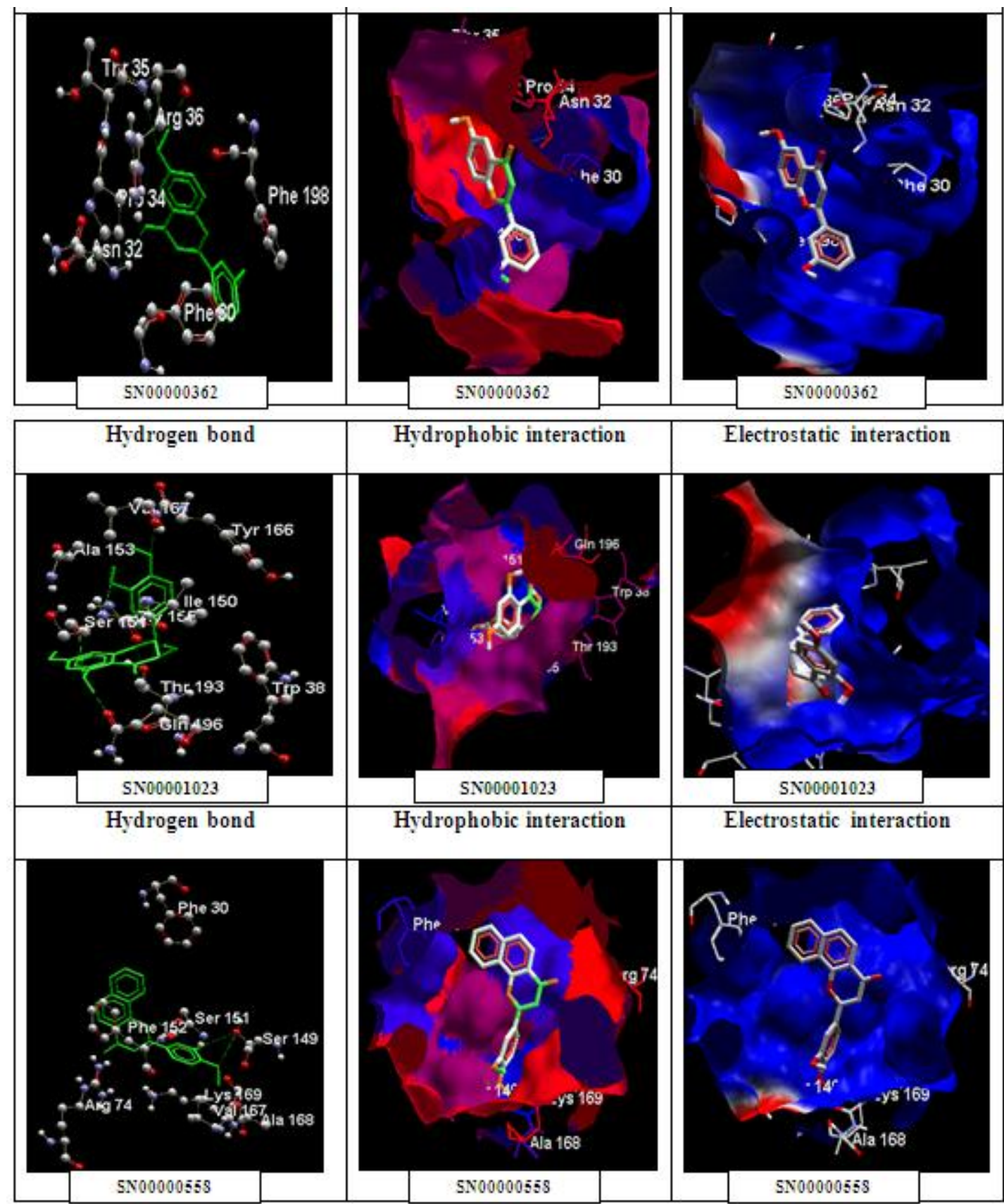

These four ligands were checked in ADMET study and found that they follow ADMET properties very well.

The bioactivity assessment of four ligands in human body is shown in table 6but onlySN00000362(6-hydroxy2-(3-methoxyphenyl) chromen-4-one) ligand is the best. 


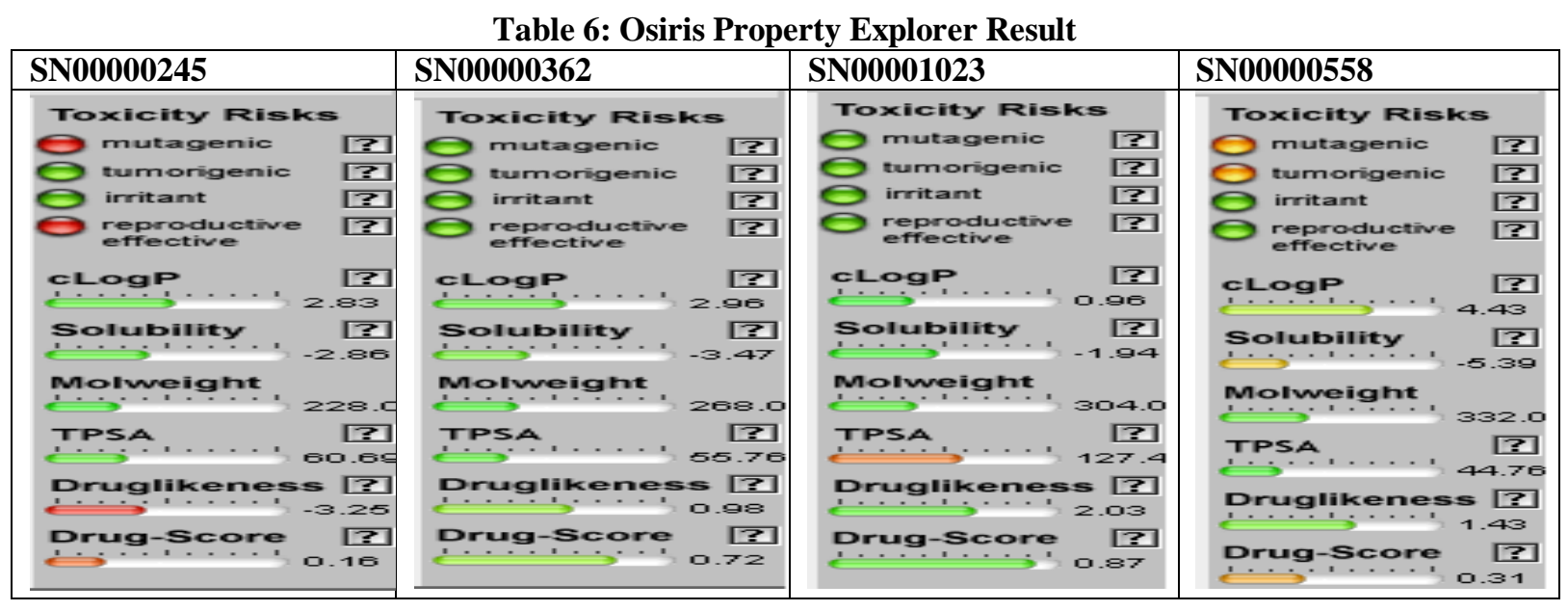

As these four proposed ligands (SN00000245, SN00000362, SN00001023, andSN00000558) have no Lipinski failures, they are bioactive compounds and following ADMET properties . They are showing good interaction with of SHC-transforming protein -1, so they can be used as a potent and an active inhibitors to these domains.

\section{Conclusion}

Drug Discovery process is a very important and crucial one in drug designing. As per interaction studies of these 80 natural compoundswithSHC-transforming protein-1, only fourligandswere found to be most energetically stable on the basis of moldock score and alsofound promisingin protein-ligandinteractions.

Out of these four screened ligands, SN00000362 (6-hydroxy-2-(3-methoxyphenyl) chromen-4-one) is quite promising at all ADMET properties except LogP. So we may conclude that SN00000362 ligand can work as $\mathrm{SHC} 1$ inhibitor and thus could be useful for controlling the obesity.

Sincere thanks to Krishna Kant Gupta and faculties.

\section{Acknowledgment}

\section{References}

[1]. Supernatural database: http://bioinf-applied.charite.de/supernatural_new/index.php

[2]. Protein data bank: http://www.rcsb.org/pdb/home/home.do

[3]. Osiris property explorer: http://www.organic-chemistry.org/prog/peo/

[4]. Lipinski filter: http://www.scfbio-iitd.res.in/software/utility/LipinskiFilters.jsp

[5]. 5-Active site predictionhttp://www.scfbio-iitd.res.in/dock/ActiveSite_new.jsp

[6]. Debbie A Lawlor and Nish Chaturvedi Treatment and prevention of obesity-are there critical periods for intervention? International Journal of Epidemiology 2006; 35:3-9 doi:10.1093/ije/dyi309.

[7]. Thomsen R, Christensen MH.MolDock: a new technique for high-accuracy molecular docking.J Med Chem. 2006 Jun 1;49(11):3315-21.

[8]. Guex N, Peitsch MC.SWISS-MODEL and the Swiss-PdbViewer: an environment for comparative protein modeling.Electrophoresis. 1997 Dec;18(15):2714-23.

[9]. http://www.nlm.nih.gov/medlineplus/news/fullstory_144204.html

[10]. http://www.nlm.nih.gov/medlineplus/obesity.html

[11]. Cynthia L. Ogden, PhD; Margaret D. Carroll, MSPH; Brian K. Kit,MD, MPH; Katherine M. Flegal, PhD Prevalence of Childhood and Adult Obesity in the United States, 2011-2012 JAMA. 2014;311(8):806-814. doi:10.1001/jama.2014.732.

[12]. Gupta AK, Ahmad AJ. Childhood obesity and hypertension. Indian Pediatr. 1990;27:333-7.

[13]. Mohan B, Kumar N, Aslam N, Rangbulla A, Kumbkarni S, Sood NK, Wander GS Prevalence of sustained hypertension and obesity in urban and rural school going children in Ludhiana. Indian Heart J. 2004;56:310-4.

[14]. A.M.Clark, B.Thornley, L.Tomlinson, C.Galletley and R.J.Norman Weight loss in obese infertile women results in improvement in reproductive outcome for all forms of fertility treatmentHuman Reproduction 1998 vol.13 no.6 pp.1502-1505, 